\title{
Determinants of Length of Hospitalization due to Acute Odontogenic Maxillofacial Infections: A 2009-2013 Retrospective Analysis
}

\author{
Rūta Rastenienè $\dot{a}^{\mathrm{J}} \quad$ Jolanta Aleksejūnienè ${ }^{\mathrm{b}} \quad$ Alina Pūrienè $^{\mathrm{a}}$ \\ ${ }^{\mathrm{a}}$ Institute of Odontology, Faculty of Medicine, University of Vilnius, Vilnius, Lithuania; ${ }^{\mathrm{b}}$ Division of Preventive and \\ Community Dentistry, Faculty of Dentistry, University of British Columbia, Vancouver, B.C., Canada
}

\section{Key Words}

Length of hospitalization - Odontogenic infections .

Determinants

\begin{abstract}
Objectives: To investigate the determinants of the length of hospitalization ( $\mathrm{LOH}$ ) due to acute odontogenic maxillofacial infections (AOMIs) from 2009 to 2013. Materials and Methods: Dental records of adult patients with AOMls and related data were retrieved from the Vilnius University's dental hospital. The $\mathrm{LOH}$ was related to several determinants in each of the following domains: outpatient primary care, severity of AOMIs, lifestyle and disease domains. Determinants were also associated with the LOH using multivariate analysis. Results: A total of 285 patients were hospitalized with AOMIs, of which 166 (58.2\%) were males and 119 (41.8\%) were females. The mean $\mathrm{LOH}$ was $8.3 \pm 4.9$ days. The bivariate analysis did not reveal any statistically significant differences in $\mathrm{LOH}$ between patients with AOMls who received urgent outpatient primary care and those who did not receive such care prior to hospitalization. All AOMI severityrelated determinants were associated with the $\mathrm{LOH}$. The $\mathrm{LOH}$ was related to coexisting systemic conditions but not to the higher severity of dental or periodontal diseases. Both
\end{abstract}

bivariate and multivariate analyses revealed similar trends, where the most significant determinants of a longer $\mathrm{LOH}$ were related to the severity of AOMIs. Conclusion: The most important determinants regarding longer hospitalization were indicators of infection severity such as an extension of the odontogenic infection and the need for an extraoral incision to drain the infection.

(c) 2015 S. Karger AG, Basel

\section{Introduction}

Acute odontogenic maxillofacial infections (AOMIs) develop due to untreated dental diseases [1]. Most AOMIs need intraoral or extraoral incisions to drain the infection [2]. While less severe AOMIs can be treated in outpatient treatment facilities, treatment of the most severe AOMIs requires costly hospitalization [3]. The length of hospitalization ( $\mathrm{LOH}$ ) has been associated with the severity of AOMIs $[4,5]$ and the presence of coexisting systemic conditions [3], among which diabetes has been identified as one of the most common medical conditions that increases a patient's overall susceptibility to infections [6]. Among patient-related risk determinants, poor oral hygiene, self-medication, inadequate use of

\begin{tabular}{ll}
\hline KARGER 125:s & $\begin{array}{l}\text { ( ) 2015 S. Karger AG, Basel } \\
1011-7571 / 15 / 0242-0129 \$ 39.50 / 0 \quad \text { Karger }\end{array}$ \\
$\begin{array}{l}\text { E-Mail karger@karger.com } \\
\text { www.karger.com/mpp }\end{array}$ & $\begin{array}{l}\text { Thisis an Open Access article licensed under the terms of the } \\
\text { Creative Commons Attribution-NonCommercial 3.0 Un- } \\
\text { ported license (CC BY-NC) (www.karger.com/OA-license), } \\
\text { applicable to the online version of the article only. Distribu- } \\
\text { tion permitted for non-commercial purposes only. }\end{array}$
\end{tabular}

Rūta Rastenienè

Institute of Odontology, Faculty of Medicine

University of Vilnius, Žalgirio 115

LT-08217 Vilnius (Lithuania)

E-Mail rasteniene.ruta@gmail.com 
medications and delayed hospitalization have been associated with the spread of acute odontogenic infections [1]. Most importantly, severe forms of AOMIs as well as delayed or unsuccessful treatment of AOMIs may lead to life-threatening complications such as mediastinitis or sepsis [7].

Given that the costs of dental care have been identified as a barrier to regular dental checkups, easily accessible and affordable primary dental care is necessary to meet the treatment needs of the most vulnerable population groups $[8,9]$. Thus, free or subsidized public dental clinics are vital to meet the health care needs of underserved population groups and patients at high risk of dental diseases [10].

To improve access to urgent primary care for patients with acute medical conditions including AOMIs, the Lithuanian National Health Care Insurance Fund has contracted multiple treatment facilities to provide such care in different locations of the country. This infrastructure allows patients with AOMIs to receive free or partly subsidized primary medical care at a dental treatment facility of their choice.

The Lithuanian health care model for the provision of urgent primary care is useful to study how the presence of free or partially subsidized access to urgent primary care in both outpatient and hospital settings impacts the $\mathrm{LOH}$ of patients treated for AOMIs. Hence, the present study investigated the determinants of the $\mathrm{LOH}$ of patients with severe AOMIs in both the outpatient and hospital settings.

\section{Materials and Methods}

The study was approved by the National Lithuanian Ethics Board. The present comprehensive retrospective study focused on the period from 2009 to 2013 and on patients with severe AOMIs hospitalized at the University Hospital. Dental records and clinical related information of adult patients, who agreed to participate in the study, were investigated.

\section{Study Variables}

The present study examined how different clinical and nonclinical determinants were related to the $\mathrm{LOH}$. The information about potential AOMI determinants was collected in four domains: (1) the Outpatient Primary Urgent Care (OPUC) related to different aspects of care provided to patients with AOMIs prior to their hospitalization. The OPUC domain included the following determinants: accessing or not accessing OPUC prior to hospitalization, waiting time prior to accessing OPUC, time when OPUC was received, costs of OPUC, seeking hospitalization after referral from OPUC and admission to a hospital. (2) The AOMI severity domain included the following determinants: anatomical spaces involved in AOMIs, extension of AOMIs (unilateral or bilateral), type of anesthesia (local or general), type of incision to drain AOMIs (intraoral or extraoral) and occurrence of complications due to AOMIs. (3) The lifestyle domain (table 1) included information about smoking, oral self-care, self-treatment when having oral pain and if dental care was sought only in the case of an emergency. (4) The disease domain (table 1) comprised information about the presence of systemic diseases, experience of dental diseases and periodontal health status.

\section{Statistical Analysis}

Statistical analysis was performed using SPSS version 21.0 software, and the threshold for statistical significance was set at $\mathrm{p}<$ 0.05 . Univariate statistics was used to test the data for normality in preparation for the inferential statistics. Given that data were normally distributed, the parametric tests were used for subsequent analysis. The bivariate analysis included the independent samples $\mathrm{t}$ test for the comparison of two groups and ANOVA with post hoc Bonferroni adjustment for the comparison of three or more groups. Linear multiple regression (LMR) models were used for the multivariate analysis.

\section{Results}

Of 285 patients with AOMIs, 166 (58.2\%) were males and $119(41.8 \%)$ were females. The mean age was $41.5 \pm$ 16.9 years (range 18-90). Of these 285 patients, 121 $(42.4 \%)$ causal teeth were lower third molars.

The mean LOH stay was $8.3 \pm 4.9$ days (range 2-29). The determinants for the provision of OPUC for patients with severe AOMIs who sought such care in different treatment facilities and locations throughout the country are shown in table 2 . Of the 285 patients with severe AOMIs, 150 (52.6\%) sought professional dental care prior to hospitalization; 121 (81.1\%) of them arrived at the hospital the same day, while the remaining 29 (19.9\%) delayed their hospitalization for different reasons for up to almost 1 week. There was no statistically significant difference in the $\mathrm{LOH}$ between the patients who sought OPUC ( $8.8 \pm 4.6$ days $)$ and the patients who did not seek OPUC (7.9 \pm 5.2 days) for their urgent dental condition $(\mathrm{p}=0.254)$. Of the 150 patients with AOMIs who sought professional dental care prior to hospitalization, 144 (96.0\%) were accessed at the OPUC the same day.

Overall, there were no statistically significant differences in the $\mathrm{LOH}$ among the patients who sought professional care immediately ( $8.7 \pm 4.7$ days) and those who delayed (9.0 \pm 8.8 days) seeking care from professionals in outpatient treatment facilities. Of the 150 patients, 130 $(86.5 \%)$ did not have any or had little OPUC-related costs. For all patients with AOMIs who visited OPUC facilities, the $\mathrm{LOH}$ and the characteristics of infection se- 
Table 1. LOH (in days) for patients with AOMIs

\begin{tabular}{|c|c|c|c|}
\hline \multirow[t]{2}{*}{ Domain } & \multicolumn{2}{|c|}{ Outpatient care prior to hospitalization } & \multirow[t]{2}{*}{$\mathrm{p}$ value } \\
\hline & yes & no & \\
\hline \multicolumn{4}{|l|}{ Domain of lifestyle determinants } \\
\hline \multicolumn{4}{|l|}{ Smoking } \\
\hline Yes & $8.6 \pm 4.4$ & $7.9 \pm 4.8$ & 0.393 \\
\hline No & $8.8 \pm 4.7$ & $7.9 \pm 5.7$ & 0.307 \\
\hline $\mathrm{p}$ value* & 0.808 & 0.969 & \\
\hline \multicolumn{4}{|l|}{ Oral self-care } \\
\hline Less than weekly & $9.0 \pm 3.9$ & $8.2 \pm 5.2$ & 0.444 \\
\hline Weekly & $8.9 \pm 5.2$ & $6.9 \pm 5.0$ & 0.069 \\
\hline Daily & $8.0 \pm 4.0$ & $8.4 \pm 5.3$ & 0.670 \\
\hline $\mathrm{p}$ value & 0.463 & 0.337 & \\
\hline \multicolumn{4}{|l|}{ Self-treatment } \\
\hline None & $9.6 \pm 4.6$ & $6.9 \pm 4.1$ & 0.022 \\
\hline Analgesics & $9.5 \pm 4.5$ & $8.1 \pm 4.6$ & 0.132 \\
\hline Antibiotics and analgesics & $8.0 \pm 4.5$ & $8.4 \pm 6.4$ & 0.712 \\
\hline $\mathrm{p}$ value & 0.138 & 0.401 & \\
\hline \multicolumn{4}{|l|}{ Visits only for emergencies } \\
\hline Yes & $7.9 \pm 3.4$ & $7.9 \pm 5.1$ & 0.997 \\
\hline No & $8.6 \pm 4.5$ & $7.9 \pm 5.8$ & 0.319 \\
\hline $\mathrm{p}$ value & 0.435 & 0.966 & \\
\hline \multicolumn{4}{|l|}{ Domain of disease determinants } \\
\hline \multicolumn{4}{|l|}{ Systemic diseases } \\
\hline Yes & $9.4 \pm 5.2$ & $11.8 \pm 9.6$ & 0.263 \\
\hline No & $8.4 \pm 4.3$ & $7.5 \pm 4.5$ & 0.103 \\
\hline $\mathrm{p}$ value & 0.244 & 0.006 & \\
\hline \multicolumn{4}{|c|}{ Dental diseases - total numbers of DMFT } \\
\hline Lowest $1 / 3$ of DMFT scores & $8.3 \pm 3.6$ & $7.4 \pm 4.3$ & 0.609 \\
\hline Middle $1 / 3$ of DMFT scores & $9.4 \pm 5.0$ & $7.2 \pm 5.4$ & 0.057 \\
\hline Highest $1 / 3$ of DMFT scores & $8.6 \pm 4.8$ & $9.4 \pm 6.5$ & 0.057 \\
\hline $\mathrm{p}$ value & 0.505 & 0.189 & \\
\hline \multicolumn{4}{|l|}{ Periodontal diseases } \\
\hline No & $7.4 \pm 3.6$ & $6.0 \pm 1.2$ & 0.193 \\
\hline Yes & $8.9 \pm 4.2$ & $6.9 \pm 5.2$ & 0.069 \\
\hline $\mathrm{p}$ value & 0.168 & 0.444 & \\
\hline
\end{tabular}

Values are expressed as mean \pm SD. DMFT $=$ Decayed, missing and filled teeth. * ANOVA with post hoc Bonferroni adjustment/independent samples t test was used.

verity are presented in table 3 . The direct determinants for disease severity were the number of anatomical spaces involved in and the extension of AOMIs, while the indirect determinants were the type of anesthesia used or the type of incision required to drain AOMIs. These determinants were statistically significantly associated with a longer $\mathrm{LOH}(\mathrm{p}<0.001)$. The LOH among patient groups with a varying number of anatomical spaces involved in AOMIs is shown in figure 1. Patients with 1 anatomical space had an overall shorter $(\mathrm{p}<0.001)$ hospital stay than those with $\geq 2$ spaces.

Acute Odontogenic Maxillofacial Infections
The 5-year cumulative incidence rate (1.4\%) of complications (mediastinitis and/or sepsis) due to AOMIs is presented in table 3. The $\mathrm{LOH}$ at the University Dental Hospital was nonsignificantly shorter for patients with complications than for those without.

Lifestyle and disease domains are reported in table 1, showing two types of vertical comparisons for the patients: those who received prior outpatient urgent care (first column) and those who did not receive prior outpatient urgent care (second column). The horizontal comparisons report the $\mathrm{LOH}$ between similar patient sub- 
Table 2. $\mathrm{LOH}$ in relation to OPUC for patients with AOMIs

\begin{tabular}{|c|c|c|c|c|}
\hline \multirow[t]{2}{*}{ Determinant of OPUC } & \multicolumn{4}{|l|}{ LOH, days } \\
\hline & $\mathrm{n}$ & mean $\pm \mathrm{SD}$ & range & $\begin{array}{l}\text { significance } \\
\text { p value* }\end{array}$ \\
\hline \multicolumn{5}{|c|}{ Receiving OPUC due to AOMIs } \\
\hline No OPUC & $135(47.4)^{\mathrm{a}}$ & $7.9 \pm 5.2$ & $2-29$ & \multirow{3}{*}{0.254} \\
\hline OPUC in a public clinic & $134(47.0)^{\mathrm{a}}$ & $8.8 \pm 4.6$ & $2-26$ & \\
\hline OPUC in a private clinic & $16(5.6)^{\mathrm{a}}$ & $7.8 \pm 3.6$ & $4-15$ & \\
\hline \multicolumn{5}{|l|}{ Time of accessing OPUC } \\
\hline Same day & $144(96.0)^{\mathrm{b}}$ & $8.7 \pm 4.6$ & $2-26$ & \multirow{3}{*}{0.598} \\
\hline Next day & $4(2.7)^{\mathrm{b}}$ & $7.5 \pm 3.5$ & $4-11$ & \\
\hline After $>2$ days & $2(1.3)^{\mathrm{b}}$ & $9.0 \pm 8.8$ & $3-15$ & \\
\hline \multicolumn{5}{|l|}{ Time of receiving OPUC } \\
\hline$<0.5 \mathrm{~h}$ & $28(18.9)^{\mathrm{b}}$ & $8.6 \pm 4.2$ & $3-17$ & \multirow{4}{*}{0.580} \\
\hline Within $1 \mathrm{~h}$ & $8(5.4)^{\mathrm{b}}$ & $10.9 \pm 4.5$ & $5-17$ & \\
\hline Within $2 \mathrm{~h}$ & $75(50.7)^{\mathrm{b}}$ & $8.5 \pm 5.0$ & $2-26$ & \\
\hline Within $3 \mathrm{~h}$ & $37(25.0)^{\mathrm{b}}$ & $8.5 \pm 3.8$ & $4-23$ & \\
\hline \multicolumn{5}{|l|}{ Costs of OPUC } \\
\hline Free & $89(60.1)^{b}$ & $8.8 \pm 4.9$ & $3-23$ & \multirow{5}{*}{0.817} \\
\hline$<10$ EUR & $39(26.4)^{\mathrm{b}}$ & $8.7 \pm 4.3$ & $2-26$ & \\
\hline $11-15$ EUR & $5(3.4)^{\mathrm{b}}$ & $8.2 \pm 3.6$ & $5-13$ & \\
\hline $16-35$ EUR & $4(2.7)^{\mathrm{b}}$ & $9.8 \pm 4.5$ & $2-15$ & \\
\hline$>36$ EUR & $11(7.4)^{b}$ & $7.2 \pm 3.3$ & $4-15$ & \\
\hline \multicolumn{5}{|c|}{ Seeking hospitalization after referral from OPUC } \\
\hline Same day & $120(81.1)^{\mathrm{b}}$ & $8.7 \pm 4.4$ & $2-23$ & \multirow{5}{*}{0.761} \\
\hline Next day & $11(7.4)^{\mathrm{b}}$ & $8.6 \pm 4.5$ & $5-17$ & \\
\hline Within 2 days & $7(4.7)^{b}$ & $7.0 \pm 2.1$ & $4-9$ & \\
\hline Within 3 days & $7(4.7)^{\mathrm{b}}$ & $10.29 \pm 7.7$ & $4-26$ & \\
\hline Within 1 week & $3(2.0)^{\mathrm{b}}$ & $9.3 \pm 6.7$ & $5-17$ & \\
\hline \multicolumn{5}{|c|}{ Time from the start of acute clinical symptoms due to AOMIs prior to hospitalization } \\
\hline$\leq 3$ days & $89(31.2)^{\mathrm{b}}$ & $8.2 \pm 4.6^{1}$ & $2-26$ & \multirow{2}{*}{0.864} \\
\hline$\geq 4$ days & $196(68.8)^{\mathrm{b}}$ & $8.3 \pm 5.0$ & $2-29$ & \\
\hline \multicolumn{5}{|c|}{$\begin{array}{l}\text { * ANOVA with post hoc Bonferroni adjustment/independent samples t test was used. } \\
\text { a Percentages of the total sample of hospitalized patients with AOMIs. }\end{array}$} \\
\hline
\end{tabular}

groups, exemplified by smokers who used OPUC and those who did not use it $(\mathrm{p}=0.393)$. There was only one statistically significant association: patients who sought outpatient urgent care prior to hospitalization and who did not treat themselves had a statistically significantly shorter $(\mathrm{p}=0.022) \mathrm{LOH}$ as compared to their counterparts who treated themselves.

Concerning disease domains, among the patients with AOMIs who were hospitalized without a prior OPUC, patients with coexisting systemic diseases had a statistically significantly longer LOH $(p=0.006)$ than those who did not have systemic diseases. Diabetic patients had a similar LOH (9.2 \pm 6.8 days) as compared to patients with other systemic diseases but without diabetes $(9.2 \pm 5.6$ days). Regarding the severity of either dental diseases or periodontal diseases, no statistically significant associations with $\mathrm{LOH}$ were found.

The joint effects of multiple determinants as measured by multivariate analysis are reported in table 4 . The dependent outcome in multivariate analyses was the $\mathrm{LOH}$. The multivariate testing was performed in two steps. Firstly, the risk determinants were tested employing four 
Table 3. Hospitalization of patients with AOMIs

\begin{tabular}{|c|c|c|c|c|}
\hline \multirow[t]{2}{*}{ Domain of severity of AOMIs } & \multicolumn{4}{|c|}{ LOH, days* } \\
\hline & $\mathrm{n}$ & mean $\pm \mathrm{SD}^{*}$ & range & $\begin{array}{l}\text { significance } \\
\text { p value }\end{array}$ \\
\hline \multicolumn{5}{|c|}{ Anatomical spaces involved in AOMIs } \\
\hline 1 & $175(61.4)$ & $7.0 \pm 4.0$ & $2-29$ & \multirow{3}{*}{$<0.001$} \\
\hline $2-3$ & $63(22.1)$ & $9.1 \pm 5.5$ & $2-29$ & \\
\hline$\geq 4$ & $47(16.5)$ & $12.1 \pm 4.8$ & $4-26$ & \\
\hline \multicolumn{5}{|l|}{ Extension of AOMIs } \\
\hline Unilateral & $267(93.7)$ & $7.9 \pm 4.5$ & $2-29$ & \multirow{2}{*}{$<0.001$} \\
\hline Bilateral & $18(6.3)$ & $15.1 \pm 5.6$ & $8-29$ & \\
\hline \multicolumn{5}{|l|}{ Anesthesia for incisions of AOMIs } \\
\hline Local & $209(73.3)$ & $6.9 \pm 3.8$ & $2-29$ & \multirow{2}{*}{$<0.001$} \\
\hline General & $76(26.7)$ & $12.4 \pm 5.2$ & $4-29$ & \\
\hline \multicolumn{5}{|l|}{ Incision for draining AOMIs } \\
\hline Intraorally & $94(33.3)$ & $5.9 \pm 2.2$ & $2-15$ & \multirow{2}{*}{$<0.001$} \\
\hline Extraorally & $191(67.0)$ & $9.6 \pm 5.3$ & $2-29$ & \\
\hline \multicolumn{5}{|l|}{ Complications of AOMIs ${ }^{\mathrm{a}}$} \\
\hline No & $281(98.6)$ & $8.38 \pm 4.9$ & $2-29$ & \multirow{2}{*}{0.738} \\
\hline Yes & $4(1.4)$ & $7.5 \pm 2.4$ & $3-14$ & \\
\hline \multicolumn{5}{|c|}{$\begin{array}{l}\text { Values in parentheses indicate percentages calculated from the total sample of hospitalized patients with } \\
\text { AOMIs. * ANOVA with post hoc Bonferroni adjustment/independent samples test was used. } \\
\text { aAll patients who developed life-threatening complications were immediately transferred to central medical } \\
\text { hospitals. }\end{array}$} \\
\hline
\end{tabular}

separate LMR analyses for each of the four domains: (1) OPUC, (2) the severity of AOMIs, (3) lifestyle, and (4) the disease domains. Then, the determinants from all four domains were tested in a joint LMR analysis.

Comparing the first four LMR models, one for each of the four domains, the only statistically significant LMR model was for the AOMI severity domain. The final joint LMR model simultaneously assessing all determinants found that extension of the acute odontogenic infection (direct indicator of severity) and use of an incision to drain the AOMIs (indirect indicator of infection severity) were the best statistically significant predictors for the longer $\mathrm{LOH}$. These two predictors jointly explained $24.9 \%\left(\mathrm{R}^{2}=0.249\right)$ of the variation in the $\mathrm{LOH}$.

\section{Discussion}

The present finding that acute odontogenic infections most frequently involved the third lower molars is consistent with findings from different countries [11-13, 16,

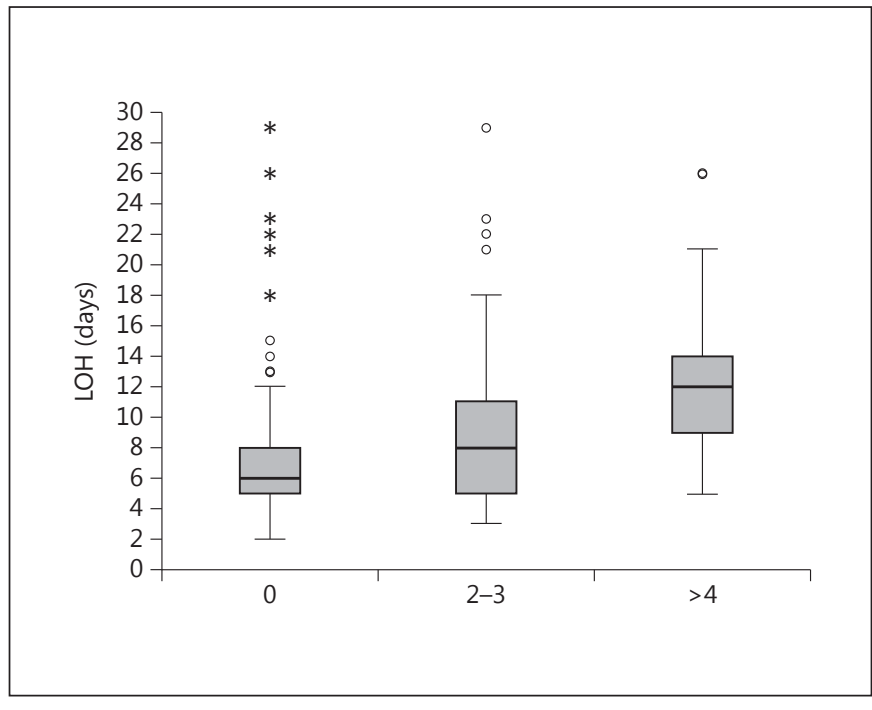

Fig. 1. Anatomical spaces involved in AOMIs.

Med Princ Pract 2015;24:129-135 DOI: $10.1159 / 000370073$ 
Table 4. Determinants of LOH due to AOMIs by LMR

\begin{tabular}{|c|c|c|c|}
\hline Outcomes of $\mathrm{LOH}$ & $\beta$ coefficient & $\mathrm{p}$ value & Tolerance \\
\hline \multicolumn{4}{|c|}{ Predictors: domain of OPUC. Selection of predictors: enter. Model summary: $p=0.642$, adjusted $R^{2}=0.030$} \\
\hline Receiving OPUC & 0.058 & 0.500 & 0.948 \\
\hline Accessing OPUC & 0.091 & 0.292 & 0.933 \\
\hline Costs of OPUC & 0.018 & 0.850 & 0.742 \\
\hline Seeking hospitalization after referral from OPUC & 0.074 & 0.440 & 0.749 \\
\hline Time from the start of symptoms to hospitalization & 0.101 & 0.263 & 0.853 \\
\hline \multicolumn{4}{|c|}{$\begin{array}{l}\text { Predictors: domain of severity of AOMIs. Selection of predictors: enter. Model summary: } p<0.001 \text {, adjusted } R^{2}= \\
0.253\end{array}$} \\
\hline Anatomical spaces involved in AOMIs & 0.218 & $<0.001$ & 0.709 \\
\hline Extension of AOMIs & 0.242 & $<0.001$ & 0.868 \\
\hline Incisions for draining AOMIs & 0.215 & $<0.001$ & 0.789 \\
\hline \multicolumn{4}{|c|}{$\begin{array}{l}\text { Predictors: domain of disease determinants. Selection of predictors: enter. Model summary: } p=0.241 \text {, adjusted } R^{2}= \\
0.042\end{array}$} \\
\hline Systemic diseases & 0.159 & 0.118 & 0.964 \\
\hline Dental diseases & 0.074 & 0.476 & 0.926 \\
\hline Periodontal diseases & 0.132 & 0.193 & 0.958 \\
\hline \multicolumn{4}{|c|}{$\begin{array}{l}\text { Predictors: domain of lifestyle determinants. Selection of predictors: enter. Model summary: } p=0.546 \text {, adjusted } \\
R^{2}=0.013\end{array}$} \\
\hline Smoking & 0.042 & 0.537 & 0.906 \\
\hline Oral self-care & 0.026 & 0.691 & 0.975 \\
\hline Self-treatment when having oral pain & 0.095 & 0.147 & 0.967 \\
\hline Dental visits only for urgency & 0.020 & 0.764 & 0.892 \\
\hline \multicolumn{4}{|c|}{ Predictors: all domains. Selection of predictors: stepwise. Model summary: $p<0.001$, adjusted $R^{2}=0.249$} \\
\hline Extension of AOMIs & 0.352 & $<0.001$ & 0.955 \\
\hline Incision (extraoral vs. intraoral) & 0.298 & 0.002 & 0.955 \\
\hline
\end{tabular}

17]. Consequently, drainage of infections is easier and the healing period shorter for patients who have AOMIs involving teeth from the upper jaw, as compared to patients with AOMIs in the lower jaw. This may be explained by anatomical and bone-related differences between the two jaws. Possibly, gravitational forces lead to a better drainage of acute odontogenic infections in the upper jaw as compared to the lower jaw [14]. Other possible explanations are the higher bone density [18] in the lower jaw and a better blood supply in the maxilla [14]. The longer hospitalization time used to treat acute odontogenic infections in the lower jaw compared to the upper jaw was reported elsewhere $[13,19]$.

The longer hospitalization time associated with coexisting systemic diseases confirmed those of previous studies regarding the involvement of, for example, diabetes [6], patients' older age [20], self-medication and delayed presentation at the hospital [1]. Therefore, timely management of acute odontogenic infections is necessary not only to avoid local complications but also to minimize systemic complications or death [21, 22].
The mean LOH of 8.3 days for patients with AOMIs at the University Hospital was within the range of 3.9-9.2 days reported previously from different countries: Iran: 9.2 days [14]; Italy: 5.2 days [23], and USA: 3.9 [3] and 5.1 days [24]. Multicenter studies might be needed to understand why the $\mathrm{LOH}$ due to severe AOMIs varies among countries. The shorter hospitalization at the University Dental Hospital for the patients with complications is explained by the fact that, following the Lithuanian Medical System guideline, all patients who develop life-threatening complications are immediately transferred to specialized central medical hospitals.

In Lithuania, the averaged annual (2009-2013) incidence rate of $<0.5 \%$ for life-threatening complications due to AOMIs was relatively low. Possibly, this relatively low incidence rate could be attributed to the Lithuanian law that stipulated that primary urgent care should be provided within a relatively short time upon arrival to a treatment facility [25].

It is important to point out that there were no statistically significant differences in the LOH between the pa- 
tients who sought OPUC treatment facilities prior to their hospitalization and those who were hospitalized without any prior outpatient primary care. These findings indicate that both groups of patients with AOMIs despite the type of urgent primary care they sought, either outpatient or hospital, received timely professional help.

\section{Conclusions}

The most important determinants of a hospitalization stay of $>8.3$ days were indicators of infection severity such as an extension of the odontogenic infection and the need for an extraoral incision to drain the infection.

\section{References}

1 Igoumenakis D, Gkinis G, Kostakis G, et al: Severe odontogenic infections: causes of spread and their management. Surg Infect 2014;15:64-68.

2 Marioni G, Rinaldi R, Staffieri C, et al: Deep neck infection with dental origin: analysis of 85 consecutive cases (2000-2006). Acta Otolaryngol 2008;128:201-206.

3 Kim MK, Nalliah RP, Lee MK, et al: Factors associated with length of stay and hospital charges for patients hospitalized with mouth cellulitis. Oral Surg Oral Med Oral Pathol Oral Radiol 2012;113:21-28.

4 Staffieri C, Fasanaro E, Favaretto N, et al: Multivariate approach to investigating prognostic factors in deep neck infections. Eur Arch Otorhinolaryngol 2014;271:2061-2067.

5 Flynn TR, Shanti RM, Hayes C: Severe odontogenic infections, part 2: prospective outcomes study. J Oral Maxillofac Surg 2006;64: 1104-1113.

6 Rao DD, Desai A, Kulkarni RD, et al: Comparison of maxillofacial space infection in diabetic and nondiabetic patients. Oral Surg Oral Med Oral Pathol Oral Radiol Endod 2010;110:e7-e12.

7 Kinzer S, Pfeiffer J, Becker S, et al: Severe deep neck space infections and mediastinitis of odontogenic origin: clinical relevance and implications for diagnosis and treatment. Acta Otolaryngol 2009;129:62-70.

8 Petersen PE: Strengthening of oral health systems: oral health through primary health care. Med Princ Pract 2014;23(suppl 1):3-9.
9 Chrisopoulos S, Luzzi L, Brennan DS: Trends in dental visiting avoidance due to cost in Australia, 1994-2010: an age-period-cohort analysis. BMC Health Serv Res 2013;13:381.

10 Slott SD: The role of free dental programs in care provision for the underserved. N C Med J 2005;66:471-474.

11 Mathew GC, Ranganathan LK, Gandhi S, et al: Odontogenic maxillofacial space infections at a tertiary care center in North India: a five-year retrospective study. Int J Infect Dis 2012;16:e296-e302.

12 Moghimi M, Baart JA, Karagozoglu KH, et al: Spread of odontogenic infections: a retrospective analysis and review of the literature. Quintessence Int 2013;44:351-361.

13 Saito CT, Gulinelli JL, Marao HF, et al: Occurrence of odontogenic infections in patients treated in a postgraduation program on maxillofacial surgery and traumatology. J Craniofac Surg 2011;22:1689-1694.

14 Pourdanesh F, Dehghani N, Azarsina M, et al: Pattern of odontogenic infections at a tertiary hospital in Tehran, Iran: a 10-year retrospective study of 310 patients. J Dent (Tehran) 2013;10:319-328.

15 Sato FR, Hajala FA, Freire FW, et al: Eightyear retrospective study of odontogenic origin infections in a postgraduation program on oral and maxillofacial surgery. J Oral Maxillofac Surg 2009;67:1092-1097.

16 Cachovan G, Phark JH, Schon G, et al: Odontogenic infections: an 8-year epidemiologic analysis in a dental emergency outpatient care unit. Acta Odontol Scand 2013;71:518-524.

17 Sanchez R, Mirada E, Arias J, et al: Severe odontogenic infections: epidemiological, microbiological and therapeutic factors. Med Oral Patol Oral Cir Bucal 2011;16:e670-e676.
18 Hwang T, Antoun JS, Lee KH: Features of odontogenic infections in hospitalised and non-hospitalised settings. Emerg Med J 2011; 28:766-769.

19 Ozsurekci Y, Tekcicek M, et al: Length of hospital stay and management of facial cellulitis of odontogenic origin in children. Pediatr Dent 2014;36:18E-22E.

$20 \mathrm{Chi} \mathrm{TH}$, Tsao YH, Yuan CH: Influences of patient age on deep neck infection: clinical etiology and treatment outcome. Otolaryngol Head Neck Surg 2014;151:586-590.

21 Seppänen L, Lauhio A, Lindqvist C, et al: Analysis of systemic and local odontogenic infection complications requiring hospital care. J Infect 2008;57:116-122.

22 Antunes AA, Avelar RL, de Melo WM, et al: Extensive cervical necrotizing fasciitis of odontogenic origin. J Craniofac Surg 2013; 24:e594-e597.

23 Boffano P, Roccia F, Pittoni D, et al: Management of 112 hospitalized patients with spreading odontogenic infections: correlation with DMFT and oral health impact profile 14 indexes. Oral Surg Oral Med Oral Pathol Oral Radiol 2012;113:207-213.

24 Jundt JS, Gutta R: Characteristics and cost impact of severe odontogenic infections. Oral Surg Oral Med Oral Pathol Oral Radiol 2012; 114:558-566.

25 Health Ministry of Lithuania. Provision of Urgent Care in Lithuania. 4-4-2004. 12-42014. http://www3.lrs.lt/pls/inter3/dokpaieska.showdoc_l?p_id=230805. 